\title{
Modelagem Matemática com Produção de Vídeos Digitais: reflexões a partir de um estudo exploratório
}

\author{
Marcelo de Carvalho Borba
}

Neil da Rocha Canedo Junior

\section{Resumo}

Este artigo propõe reflexões a respeito de um estudo exploratório focado em um método de ensino que integra a modelagem com a produção de vídeos digitais, em Educação Matemática. Consiste em uma forma de desenvolver trabalhos com modelagem na qual uma atividade de modelagem é apresentada por meio de um vídeo digital, e os alunos são desafiados a produzirem um vídeo como resposta. $\mathrm{O}$ estudo se desenvolveu sob as lentes teóricas do construto seres-humanos-com-mídias e da semiótica social, e nos permitiu refletir e conjeturar a respeito das possibilidades que emergem dessa prática pedagógica em modelagem, na qual o vídeo digital se torna um ator.

Palavras-chave: Modelagem. Análise Multimodal. Seres-humanos-commídias. Tecnologias Digitais. 


\title{
Mathematical Modelling with Digital Video Making: Reflections from an Exploratory Study
}

\author{
Marcelo de Carvalho Borba \\ Neil da Rocha Canedo Junior
}

\section{Abstract}

This paper reflects on an exploratory study focused on a teaching methodology that integrates modeling with digital video production in mathematical education. We describe the development of a paradigm where a modeling activity is presented through digital video, and students are challenged to create a video in response. The study, developed under the theoretical lenses of the human-with-media construct and social semiotics, allows us to reflect and conjecture about the possibilities that emerge from this modeling pedagogical practice, in which digital video becomes an actor.

Keywords: modelling. Multimodal analisys. Humans-with-media. Digital technologies. 


\section{Introdução}

O objetivo deste artigo é propiciar reflexões sobre um estudo exploratório voltado para uma metodologia de ensino que procura integrar a modelagem com a produção de vídeos digitais, em educação matemática. Essa prática de ensino configura o objeto de estudos da pesquisa acadêmica do segundo autor deste texto, e se encontra em fase de desenvolvimento, sob a orientação do primeiro autor. Dessa forma, o estudo exploratório a que este artigo se dedica configura uma espécie de piloto, ou seja, uma experiência prévia com o potencial de refinar os objetivos e contribuir com as escolhas referentes ao design metodológico da pesquisa em questão. A pesquisa integra as ações do Grupo de Pesquisa em Informática, Outras Mídias e Educação Matemática (GPIMEM²3) e se associa ao projeto de pesquisa: Vídeos digitais na licenciatura em Matemática a distância (e-licm@t-tube), apoiado pelo Conselho Nacional de Desenvolvimento Científico e Tecnológico (CNPq), a partir dos editais produtividade em pesquisa (processo: 303326/2015-8) e universal (processo: 400590/2016-6).

A relação entre a modelagem e as tecnologias digitais é tema de pesquisas e ações educacionais desenvolvidas no GPIMEM desde seus primórdios, que datam de 1993. Essa relação surge com o uso de calculadoras gráficas e softwares gráficos (BORBA; MENEGHETTI; HERMINI, 1997; ARAÚJO, 2002), passa pela presença da internet como fonte de informações (diniz, 2007; diniz; Borba, 2012), e aborda a realização de trabalhos de modelagem em ambientes online (Malheiros, 2008; Malheiros; Franchi, 2013; Galleguillos, 2016; Galleguillos; Borba, 2018).

Mais recentemente, os esforços investigativos do grupo têm se voltado para o potencial dos vídeos digitais na educação matemática. Pesquisas como as que foram desenvolvidas por Oechsler (2018), Oliveira (2018) e Fontes (2019) buscaram explorar as potencialidades educacionais dessa tecnologia digital em metodologias de ensino que destacam a produção de vídeos por parte dos alunos. Além dessas atividades de pesquisa, o GPIMEM realiza ações educacionais, tais como minicursos, cursos de extensão universitária, etc., nas quais a produção de vídeos é tematizada. Dentre essas ações, destacamos o festival de vídeos digitais em educação matemática ${ }^{24}$, cuja primeira edição aconteceu em 2017, e vem sendo realizado anualmente, desde então.

A combinação da modelagem com a produção de vídeos foi abordada, no contexto das pesquisas desenvolvidas no GPIMEM, por Domingues (2014), que buscou compreender como os alunos de uma disciplina de Matemática Aplicada à Biologia incluíam os vídeos digitais em seus trabalhos com modelagem. A revisão de literatura que temos realizado mostra que essa

$23<$ https://igce.rc.unesp.br/\#!/gpimem>

$24<$ www.festivalvideomat.com> 
última pesquisa, que também é apresentada em Domingues e Borba (2017), configura uma das poucas que tematizam o uso de vídeos digitais em práticas de modelagem.

Cabe pontuarmos, as diferenças entre metodologia de pesquisa e de ensino. A metodologia de pesquisa se refere aos métodos mobilizados, ou caminhos percorridos, ao longo da investigação até sua sistematização, o que envolve fazer escolhas na busca por compreensões e interpretações em torno de uma interrogação formulada. A metodologia de ensino, por sua vez, diz do planejamento e da mobilização de esforços e recursos no sentido de favorecer a produção de conhecimentos no âmbito de uma ação educacional. Ambas envolvem pressupostos teóricos, crenças, concepções e visão de conhecimento (Borba; Almeida; Gracias, 2018).

O design da metodologia de ensino, à qual este artigo se dedica, tem sido pensado a partir da perspectiva epistemológica de que o conhecimento resulta das inter-relações dos atores humanos com as distintas tecnologias da inteligência, ou mídias, no âmbito de coletivos pensantes de seres-humanos-com-mídias (BORBA; VILLARREAL, 2005). Consiste em uma maneira de desenvolver trabalhos com modelagem em que uma problemática é apresentada por um vídeo digital (videoproblema de modelagem) que, além de expor uma temática, trazer algumas informações e propor questões, desafia os alunos a produzirem um vídeo como resposta (videorresposta de modelagem), promovendo a integração entre modelagem e produção de vídeos digitais.

O estudo exploratório que apresentamos neste artigo toma como objeto a aplicação da referida metodologia de ensino no contexto de um minicurso apresentado no VII Encontro Mineiro de Educação Matemática (VIII EMEM²5), voltado para professores em formação inicial e continuada, no qual o segundo autor atuou como professor. Esse estudo se baseou nas observações do professor sobre a participação dos alunos nas atividades de modelagem e produção de vídeos desenvolvidos nesse contexto e na videorresposta de modelagem aí produzida. A partir dessas observações e sob os olhares teóricos do construto seres-humanoscom-mídias (BORBA; VILLARREAL, 2005) e da semiótica social (KRESS, 2009; BEZEMER; JEWITT, 2010; O'HALLORAN, 2012; OECHSLER, 2018), apresentamos algumas reflexões e conjecturas a respeito das possibilidades dessa proposta de integração entre modelagem e produção de vídeos.

No intuito de concretizar os objetivos deste artigo, estruturamos a escrita da seguinte maneira. Na próxima seção, aprofundaremos a discussão sobre modelagem, no sentido de situar a metodologia de ensino em estudo diante das nossas perspectivas de modelagem, e também das concepções de outros autores. Em seguida, apresentaremos um diálogo entre os pressupostos do construto seres-humanos-com-mídias e da semiótica social. As duas seções

25 Evento realizado na cidade de Ituiutaba (MG), de 11 a 14 de novembro de 2018. 
subsequentes são dedicadas ao estudo exploratório desenvolvido a partir das lentes teóricas supracitadas. E a última traz as nossas considerações finais a respeito do que foi exposto ao longo do artigo.

\section{Modelagem: uma perspectiva}

A modelagem é uma prática pedagógica que tem origens na matemática aplicada, de onde guarda raízes e influências (BIEMBENGUT; HEIN, 2000; BASSANESI, 2002; MEYER; CALDEIRA; MALHEIROS, 2011). Ao longo das últimas três décadas, uma comunidade de pesquisadores vem se constituindo em torno dessa temática, nos cenários nacional e internacional, de maneira que se constitui em uma tendência emergente em educação matemática (BIEMBENGUT, 2009; STILLMAN; BLUM; BIEMBENGUT, 2015). Nesse contexto, diferentes concepções de matemática e de conhecimento deságuam em maneiras diversas de compreender e fazer modelagem. Isso resulta em uma multiplicidade de metodologias de ensino inspiradas nessa tendência, o que também influencia maneiras distintas de pensar os designs metodológicos das pesquisas que se debruçam sobre essa região de inquérito.

Em linhas gerais, a modelagem pode ser compreendida como o processo de resolução de problemas de aplicação da matemática a contextos não matemáticos. Consiste na tradução dos objetos, fenômenos, variáveis e relações, observados na situação não matemática problematizada, para o domínio da matemática, o que resulta na elaboração de um modelo matemático, ou seja, uma representação, em linguagem matemática, da situação à qual o problema faz referência. Esse processo é repetido, na forma de ciclos de modelagem, até que os resultados obtidos sejam satisfatórios frente aos objetivos do problema (Bassanesi, 2002; Blum, et al., 2007; Blum, 2015).

Figura 1: O processo de modelagem descrito em sete passos.

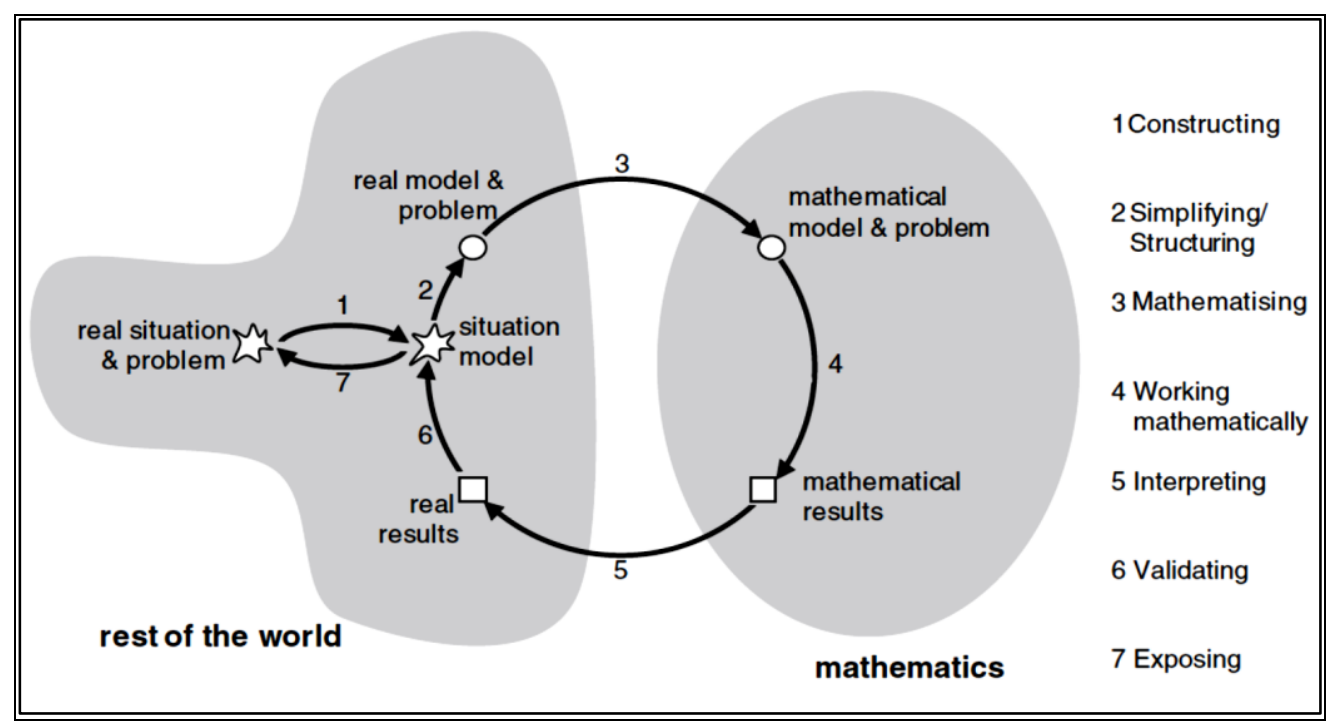

Fonte: Blum (2015, p. 76).

ISSN 2526-2882 
A literatura apresenta diferentes versões para esse ciclo de modelagem e, em muitas delas, ele aparece dividido em fases, ou etapas, como as que aparecem na Figura 1. Essa maneira de compreender os processos de modelagem remete à matemática aplicada, ou seja, busca descrever a atividade dos modeladores matemáticos profissionais. Acreditamos que a compreensão da atividade desses profissionais contribui, em certa medida, para um melhor entendimento da modelagem enquanto prática pedagógica, “acontece que, para pegá-la e levála para a sala de aula, temos que considerar uma variável nova e muito importante: em salas de aula, existem alunos" (MEYER; CALDEIRA; MALHEIROS, 2011, p. 38).

Essa diferença de contexto entre a matemática aplicada e a educação matemática é discutida em Burak (2016) ao longo de sua própria trajetória de pesquisador, que acompanha a maneira como suas concepções de modelagem foram se constituindo. Ele relata que, na fase inicial, "a visão sobre a modelagem recaía na visão mais usual da matemática aplicada" (BURAK, 2016, p. 36), de forma que a compreensão do processo de modelagem era pautada na elaboração do modelo matemático, em si. A experiência adquirida no trabalho com a formação de professores influenciou a perspectiva de modelagem desse autor, no sentido de compreendê-la como uma prática pedagógica, descrita a partir de etapas que remetem a uma metodologia de ensino. São elas: 1) escolha do tema; 2) pesquisa exploratória; 3) levantamento do(s) problema(s); 4) resolução do(s) problema(s) e o trabalho dos conteúdos matemáticos no contexto do tema; e 5) análise crítica da(s) solução(ões) (BURAK, 2016, p. 37).

A perspectiva de modelagem apresentada em Almeida e Vertuan (2011, p. 22) também coloca a sala de aula em primeiro plano, ao destacar que a introdução de trabalhos com modelagem "vem revestida de intenções e interesses de professores e alunos". Os autores ressaltam a importância de familiarizar os alunos com as práticas de modelagem de forma gradativa. Nas primeiras experiências com modelagem, cabe ao professor apresentar uma problemática extramatemática, juntamente com os dados e informações necessárias à construção de um modelo matemático, em um processo em que os alunos devem ser acompanhados, passo a passo. No decorrer desse convívio com a modelagem, os alunos se tornam responsáveis pela condução da atividade, cabendo a eles a identificação da problemática, a coleta de dados, bem como a elaboração e validação do modelo.

Da perspectiva epistemológica assumida neste artigo, compreendemos a modelagem como um processo de produção de conhecimentos do qual participam não apenas os atores humanos, dentre os quais alunos e professores, mas também as atrizes tecnológicas (mídias), em um coletivo pensante de seres-humanos-com-mídias (BORBA; VILLARREAL, 2005). As ações desse coletivo incluem: propor questões e levantar hipóteses (problematizar), testar hipóteses, levantar informações e mobilizar estratégias na busca por respostas (investigar), o que envolve lançar mão de conceitos e procedimentos matemáticos (matematizar). 
Essa perspectiva de modelagem se aproxima daquela apresentada em Borba e Villarreal (2005), pela qual o processo de modelagem inclui não apenas a solução de problemas extramatemáticos, mas também a proposição de problemas dessa natureza por parte dos alunos. Além disso, a visão de conhecimento que aqui assumimos inclui considerar que as mídias moldam a própria noção de problema (BORBA, 2009). Uma consequência disso é que uma problemática com o potencial de desencadear processos de problematização, investigação e matematização, quando na presença de determinadas mídias, a exemplos do lápis e do papel, pode degenerar na aplicação direta de recursos disponíveis em softwares, aplicativos digitais, ou na internet. Entendemos que essa maneira de compreender os processos de modelagem é dissonante com a possibilidade de interpretá-los a partir de ciclos compostos de etapas previstas, uma vez que concebemos os coletivos de seres-humanos-com-mídias com o potencial de moldar a própria estrutura e natureza desses processos.

$\mathrm{Na}$ tradição das pesquisas em modelagem desenvolvidas no GPIMEM, a ação de diferentes tecnologias (mídias) é investigada no âmbito de atividades desenvolvidas na perspectiva dos projetos de modelagem, que consiste em uma maneira de desenvolver trabalhos com modelagem a partir de temáticas propostas pelos estudantes (ARAÚJO, 2002; BORBA; VILLARREAL, 2005). Domingues (2014) segue essa tradição, ao explorar as possibilidades dos vídeos digitais no contexto de uma disciplina que envolvia, dentre outras atividades, o desenvolvimento de projetos de modelagem. Conforme o autor pode considerar, essa tecnologia participou desses projetos tanto como fonte de informações, obtidas a partir de vídeos assistidos pelos alunos, assim como se constituiu em uma maneira de apresentar os resultados desses trabalhos com modelagem, por meio de vídeos produzidos pelos próprios alunos (c. F. DOMINGUES; BORBA, 2017).

Diferente de Domingues (2014), que acompanha a tradição dos projetos de modelagem, o estudo exploratório que apresentamos neste artigo foca em uma metodologia de ensino pensada no intuito de explorar outras potencialidades para o vídeo digital em trabalhos com modelagem. Em certos aspectos, ela se aproxima daquela que foi investigada em Soares (2012), baseada na análise de modelos matemáticos, em que os processos de modelagem se iniciam a partir de um modelo matemático apresentado por meio da interface do software modellus, tornando essa mídia uma protagonista no processo (c. F. SOARES; BORBA, 2014).

Em termos mais específico, na metodologia de ensino tematizada nesse artigo, o processo de modelagem se desenvolve a partir da exibição de um vídeo digital (videoproblema de modelagem), de maneira que uma mídia entre em ação na proposição de uma problemática extramatemática. Esse vídeo expõe um tema, sobre o qual traz algumas informações e levanta questões, e desafia os alunos a produzirem, eles próprios, um vídeo como resposta (videorresposta de modelagem). Ao incluir a elaboração de um vídeo pelos alunos, essa prática 
letiva promove a integração da modelagem com a produção de vídeos digitais, em educação matemática.

A proposta dessa metodologia de ensino considera elaborar videoproblemas de modelagem no sentido de favorecer que novas questões possam ser levantadas pelos alunos, a partir do que é apresentado no vídeo. A intenção é que as ações de problematizar, assim como investigar e matematizar, sejam atributos de coletivos pensantes de seres-humanos-commídias, que incluem alunos, professores, vídeo digital, dentre outros atores humanos e tecnológicos. Dessa maneira, os alunos não se tornam meros objetos de uma atividade pensada pelo professor, que lhes é apresentada por meio da mídia vídeo digital, remetendo a uma versão permeada por recursos audiovisuais de uma educação bancária (FREIRE, 2011). Essa metodologia de ensino, que aproxima a modelagem da produção de vídeos, configura um desdobramento da perspectiva pedagógica que envolve a relação entre mídias digitais e modelagem, ao longo de 25 anos de estudos nessas temáticas no GPIMEM.

\section{Seres-humanos-com-mídias e semiótica social: olhares teóricos}

$\mathrm{Na}$ perspectiva do construto teórico seres-humanos-com-mídias, a produção de conhecimentos envolve ações de um coletivo pensante composto por atores humanos e mídias. Essas últimas são entendidas como atrizes não humanas, que mais que acessórios das ações humanas, assumem poder de ação nesses processos. Nesse sentido, conhecimentos produzidos na presença de lápis e papel tendem a ser qualitativamente distintos daqueles produzidos em coletivos em que softwares e aplicativos digitais estão presentes (BORBA; VILLARREAL, 2005).

Essa concepção epistemológica inspira-se no trabalho de Tikhomirov (1981), que apresenta uma visão teórica em que as tecnologias computacionais reorganizam o pensamento humano de maneira similar, mas qualitativamente distinta de outras tecnologias como a oralidade e a escrita. Essa maneira de perceber as relações entre humanos e computadores rompe com as teorias da substituição e da suplementação, vigentes na década de 1970, pelas quais se estabelecia uma relação dicotômica entre humanos e computadores.

Outra fonte de influências da visão de conhecimento subjacente ao construto sereshumanos-com-mídias é a noção de tecnologias da inteligência, apresentada em Lèvy (1993), pela qual é assumido que a produção de conhecimentos é fruto de uma rede composta por humanos e as distintas tecnologias da inteligência, são exemplos: a oralidade, a escrita, e as tecnologias informáticas. Para esse autor, o advento de uma nova tecnologia estabelece ecologias cognitivas distintas daquelas que figuravam em tempos históricos anteriores a ela.

No que se refere à multimodalidade, ou abordagem multimodal, podemos interpretála, em linhas gerais, como uma forma de compreender os processos comunicativos para além da oralidade e da escrita, ao incluir a percepção de gestos, olhares, feições faciais, e outros 
recursos mobilizados nas ações enunciativas e na produção de significados para as mesmas. Isso inclui a música e toda uma variedade de efeitos sonoros, imagens estáticas ou animadas, a escrita e o desenho na lousa, apresentações por meio de recursos multimídia, exibição de vídeos, etc. (KRESS, 2009; BEZEMER; JEWITT, 2010; O’HALLORAN, 2012; OECHSLER, 2018).

Dentre as muitas abordagens referentes à análise multimodal, destaca-se a semiótica social, que considera a linguagem e seus significados como instâncias culturais, e estende suas compreensões a toda a gama de modos de representação e comunicação empregados em uma cultura. O modo configura a unidade básica analítica dos processos de comunicação e interpretação de significados, e refere-se ao conjunto organizado de todos os recursos mobilizados em um evento comunicativo e interpretativo (KRESS, 2009; BEZEMER; JEWITT, 2010).

No entendimento de Bezemer e Jewitt (2010), a semiótica social assume três pressupostos fundamentais. O primeiro refere-se à completude, ao considerar que a análise deve centrar-se na descrição do repertório completo dos recursos de comunicação e interpretação de significados mobilizados. O segundo diz respeito à contextualidade dos processos comunicativos e interpretativos, os quais são condicionados a fatores culturais. E o terceiro remete à interdependência entre os modos mobilizados na comunicação e produção de significados, uma vez que os significados referentes a distintos modos envolvidos no processo estão sempre entrelaçados em uma rede.

Ao assumirmos esses pressupostos teóricos da análise multimodal, na perspectiva da semiótica social (KRESS, 2009; BEZEMER; JEWITT, 2010), a partir da visão de conhecimento subjacente ao construto teórico seres-humanos-com-mídias (BORBA; VILLARREAL, 2005), deparamo-nos com possibilidades analíticas dos processos comunicativos e interpretativos em que as mídias, mais que acessórios incorporados aos modos de comunicação e interpretação de significados, tornam-se atrizes com o poder de moldar tais processos. Em termos dessas visagens teóricas podemos considerar, a título de exemplo, que uma fala acompanhada do gesto de apontar para uma imagem, ou expressão matemática, desenhada em uma lousa, configura um modo distinto daquele em que a mesma fala e o mesmo gestual se dirigem à mesma imagem, ou expressão matemática, só que, agora, não mais desenhada de forma estática em uma lousa, mas apresentada por meio de uma tela que lhes confere animação, que pode vir acompanhada de uma gama de efeitos audiovisuais.

A produção de vídeos digitais envolve recursos que permitem combinar imagens estáticas, sons diversos, com imagens em movimento, as quais podem ser obtidas tanto por meio da filmagem de objetos físicos e pessoas, como a partir da captura de animações na tela de um software (MOLETTA, 2019). Essa combinação de sons, imagens e efeitos variados na composição de um vídeo traz heranças da montagem cinematográfica, que consiste na arte de 
cortar e reorganizar as partes de um filme, sendo objeto de estudos no campo da sétima arte desde os tempos do cinema mudo (EISENSTEIN, 2002).

Nos dias de hoje, a possibilidade de produzir vídeos e áudios em formato digital, por meio de câmeras e gravadores de áudio, muitas vezes acoplados aos modernos aparelhos celulares (smartphones), popularizou a produção desses materiais fílmicos. Com a democratização do acesso a essas tecnologias, os softwares de edição de vídeos, antes restritos ao uso profissional, em razão das dificuldades operacionais e do custo elevado, hoje são de fácil manuseio e podem ser adquiridos ou acessados de forma gratuita, ou a preços accessíveis, a partir da internet, ou baixados, para usar uma terminologia ressonante com a cultura digital emergente (MOLETTA, 2019).

Agora se tornou possível editar um vídeo no computador, na própria câmera de vídeo ou mesmo em alguns aparelhos celulares (capazes de captarem imagens em qualidade suficiente para exibição em emissoras de televisão), variando em cada um dos casos a diversidade de recursos (RENÓ, 2019, p. 52$53)$.

Nas atividades educacionais e nas pesquisas desenvolvidas no âmbito do GPIMEM, verifica-se crescente presença desses recursos de edição na produção de vídeos. Esse incremento dos recursos de edição se faz perceber, por exemplos: nos vídeos submetidos ao festival de vídeos digitais e educação matemática; nos vídeos produzidos por alunos em nossos cursos de extensão; e nas pesquisas desenvolvidas no grupo (Oechsler, 2018; Oliveira, 2018; Fontes, 2019), e naquelas ainda em fase de desenvolvimento.

Sob os olhares teóricos da semiótica social e do construto seres-humanos-commídias, faz sentido considerar que a presença cada vez maior desses recursos de edição - ou seja, dessas mídias - favorece a diversificação dos modos de comunicar e interpretar significados que podem ser mobilizados quando alunos e professores são incentivados a assistir e a produzir vídeos digitais. E isso sugere que essas teorizações, enquanto princípios analíticos, podem contribuir na compreensão de situações pedagógicas em que os vídeos digitais se tornam atores educacionais, o que nos remete à experiência educacional tomada como objeto de reflexões no estudo apresentado neste artigo, o qual será descrito nas seções subsequentes.

\section{O contexto e o videoproblema}

A atividade com modelagem e produção de vídeos que passamos a descrever, e refletir sobre, foi desenvolvida em um minicurso realizado no VIII Encontro Mineiro de Educação Matemática (VIII EMEM), nos dias 12 e 13 de outubro de 2018. O minicurso foi apresentado presencialmente pelo segundo autor desse texto, na condição de professor, e contou com a presença de nove participantes, dentre alunos da licenciatura em Matemática e da pós- 
graduação em Matemática e em educação matemática, e professores de Matemática de todos os níveis educacionais.

O minicurso iniciou com a apresentação dos participantes, quando convidados a se manifestarem sobre seus interesses educacionais e/ou profissionais, e a relação desses com a temática do curso. A partir dessas informações, constatamos que boa parte deles tinha certa familiaridade com a produção de vídeos, adquirida em experiências pedagógicas vivenciadas na condição de alunos e/ou professores.

Após essa apresentação e uma discussão introdutória sobre produção de vídeos e modelagem, o professor exibiu um vídeo que propunha uma atividade de modelagem sobre a temática do consumo da água, o título do referido vídeo é: Água: por um consumo consciente. No vídeo, temos duas personagens, uma delas é o próprio professor do minicurso e a outra o seu filho, então com oito anos de idade. A figura 2 apresenta uma imagem de uma das cenas do filme, juntamente o qr code - recurso que permite assistir o vídeo, na íntegra, pelo smartphone. $\mathrm{O}$ vídeo pode ser acessado, também, a partir do youtube, em: $<$ www.youtube.com/watch?v=oqeh1uf6mog $>$.

Figura 2: Imagem de uma cena do videoproblema junto ao qr code de acesso ao vídeo.

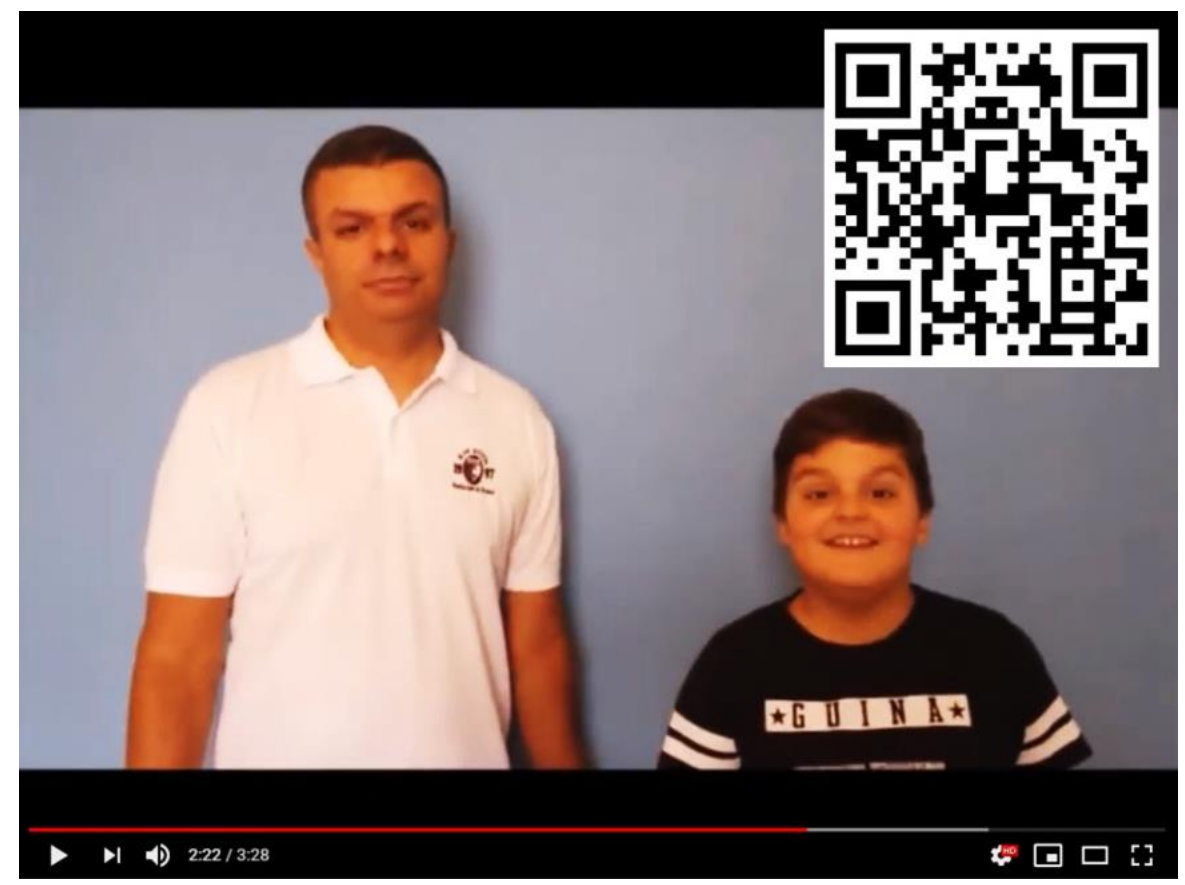

Fonte: videoproblema produzido pela equipe do GPIMEM

Vale mencionar que os participantes do minicurso não receberam qualquer informação do professor sobre como seria a dinâmica da atividade, além do que é apresentado no vídeo. Esse vídeo divide-se em 5 etapas, ou trechos, apresentadas ao longo das cenas a partir de subtítulos, que consistem de mensagens escritas que aparecem na tela entre uma etapa e 
outra, quais sejam: na hora do banho, coletando a água, medindo a água, refletindo, e agora um desafio.

Ao olhar o vídeo das perspectivas teóricas assumidas neste artigo, entendemos que em cada uma dessas etapas foram mobilizados modos distintos de comunicação de significados. Na primeira parte, na hora do banho, temos a filmagem do garotinho falando, primeiramente, sobre a importância da água para nós e para a vida no planeta, em geral. Essa oralidade direta, que se refere à filmagem do próprio falante, aparece acompanhada de legendas, que pontuam os trechos mais importantes da fala.

Em seguida, o garoto convida os espectadores a acompanhar a medida da quantidade de água que o chuveiro de sua casa gasta em 10s de funcionamento. Essa medida da água ocupa as cenas da segunda e da terceira etapas. Na segunda, é mostrado, em segundo plano, um balde de água no qual a água do chuveiro é colhida e, em primeiro plano, a tela de um aparelho celular no modo cronômetro. A cena consiste em mostrar o balde sendo colocado embaixo do chuveiro em funcionamento no momento em que o cronômetro é acionado, e retirado rapidamente no momento em que a marca de 10 s é atingida (Figura 3).

Nesse trecho do vídeo, a oralidade não está presente, e a escrita se resume aos números referentes à cronometragem da tela do celular. Os atores humanos atuam nos bastidores, manipulando essas mídias, que figuram como as atrizes principais desses modos comunicativos.

Figura 3: Cena da coleta da água consumida em $10 \mathrm{~s}$.

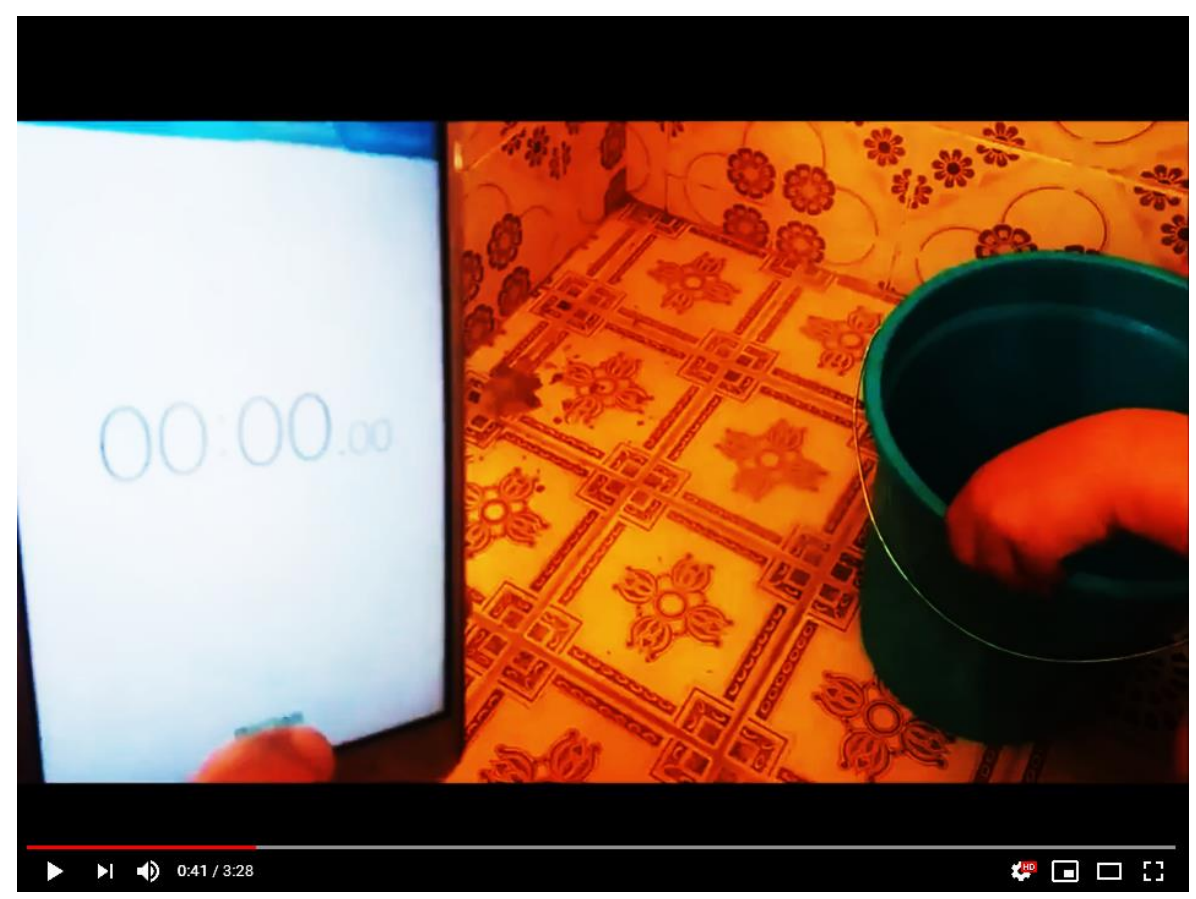

Fonte: videoproblema produzido pela equipe do GPIMEM 
Na etapa seguinte, medindo a água, surge a imagem estática de um copo de medida, desses comuns ao uso doméstico (Figura 4), no qual a água do balde é despejada. Primeiramente, são despejados $500 \mathrm{ml}$, que consiste da capacidade máxima do copo e, em seguida, o restante da água, um volume de $300 \mathrm{ml}$. Nesse trecho do vídeo, a oralidade aparece na forma de uma narração que procura explicar o processo de medida da água, acompanhada de legendas que reforçam a informação referente ao valor da medida dessa quantidade de água, a saber: $800 \mathrm{ml}$. A narrativa (oralidade), a escrita na forma de legenda, e a filmagem da água despejada no copo de medida, no qual temos a escrita dos valores das escalas de medidas, compõem os modos comunicativos presentes nessa etapa do vídeo.

Figura 4: Cena da medição do volume da água consumida em $10 \mathrm{s.}$

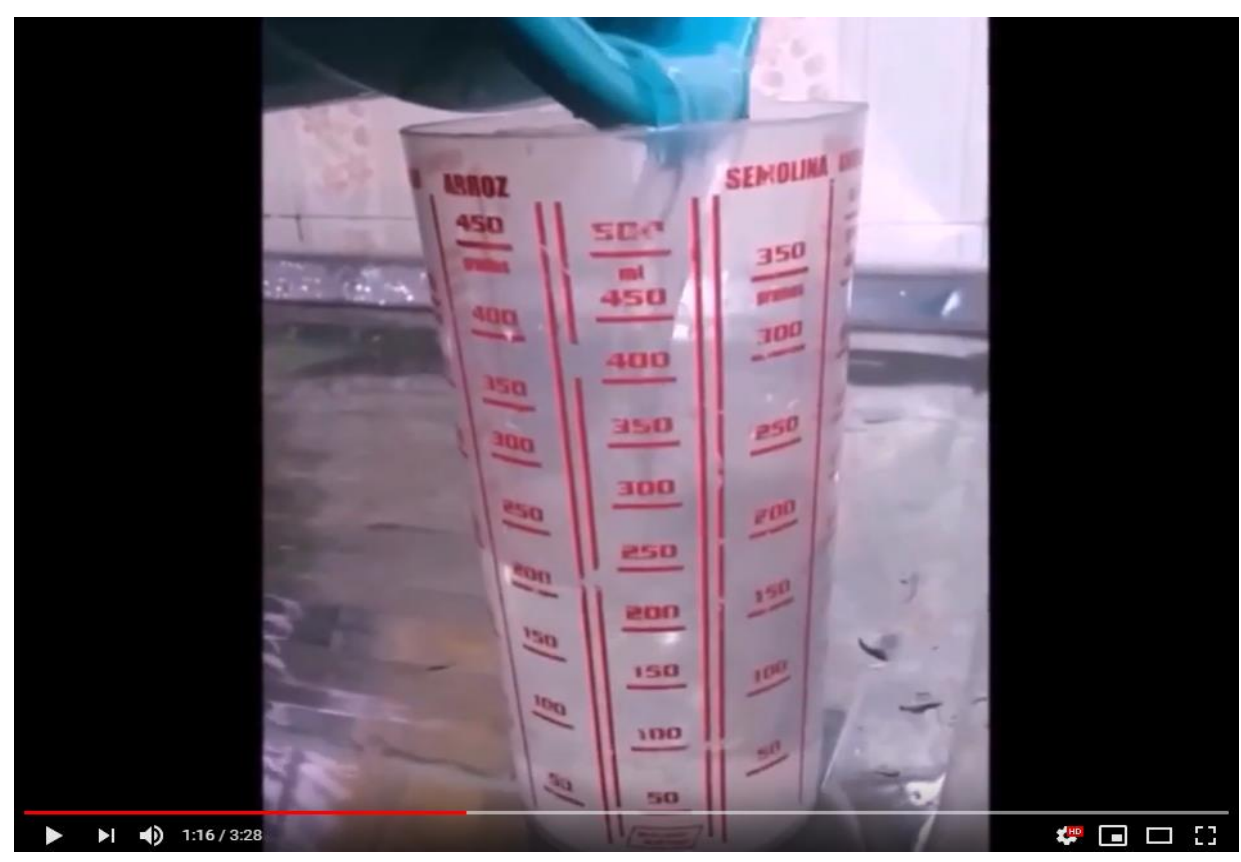

Fonte: Videoproblema produzido pela equipe do GPIMEM.

Na quarta etapa, que aparece no vídeo sob o título refletindo, são apresentados alguns dados e questões para reflexões. As cenas consistem de uma sequência de quatro fragmentos de texto, como mostra a Figura 5, que foram apresentados acompanhados da narrativa que repetia, a exceção de alguns sinônimos, o que estava escrito nos textos.

$\mathrm{O}$ primeiro texto apresenta um dado obtido em um documento publicado pelo ministério do meio ambiente (BRASIL, 2005), o qual afirma que um chuveiro consome, em média, 150 litros de água a cada 10 minutos de funcionamento. No segundo, temos uma pergunta que sugere uma comparação entre esse valor e aquele que obtido empiricamente por meio do processo de medida descrito nos trechos anteriores do vídeo, que foi de $800 \mathrm{ml} \mathrm{de}$ água a cada $10 \mathrm{~s}$. 
Figura 5: Sequência das quatro cenas que apresentam alguns dados e questões para reflexão.

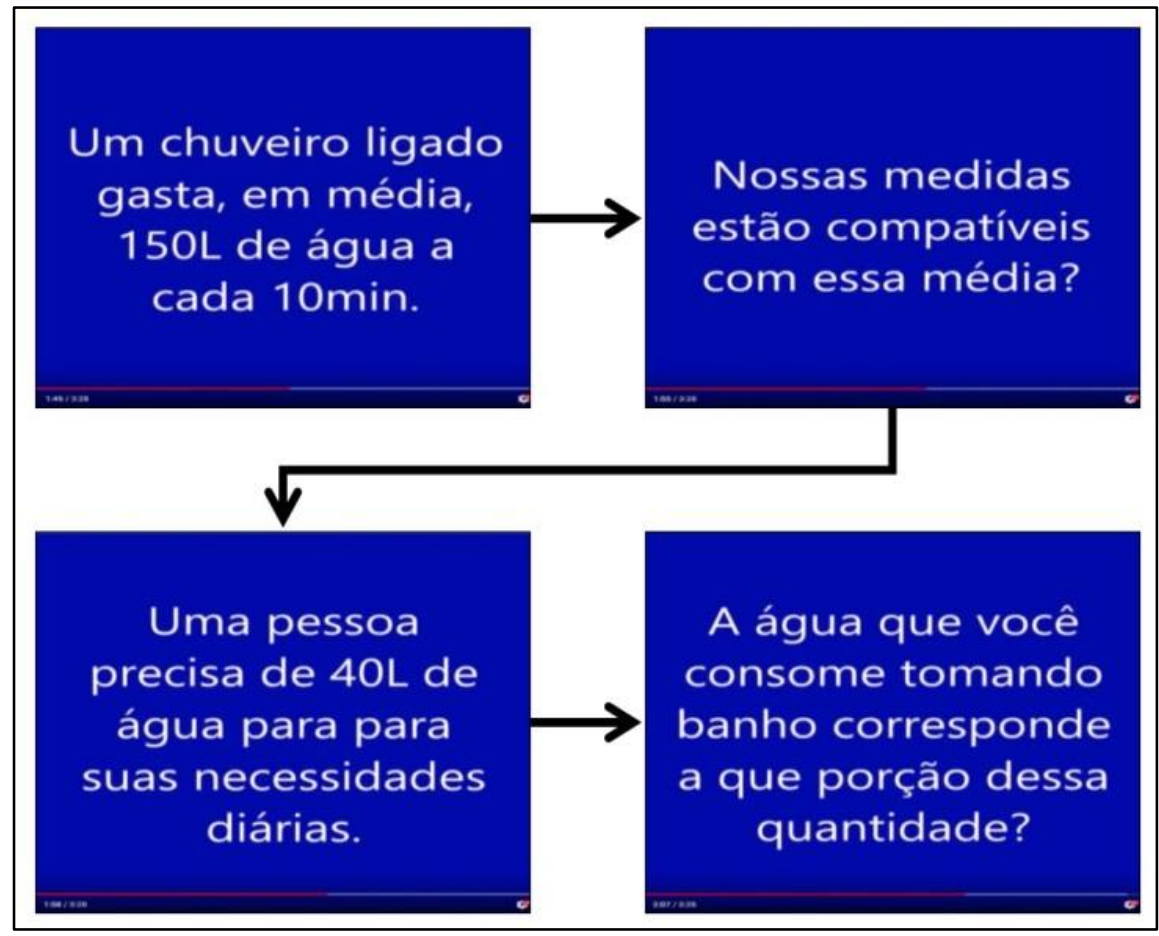

Fonte: Videoproblema produzido pelo GPIMEM

O terceiro texto apresenta outro dado do Ministério do Meio Ambiente, sugerindo que 40 l são o mínimo de água que uma pessoa necessita para suas necessidades diárias. E o quarto propõe uma pergunta que convida os espectadores do vídeo a compararem a água que consomem, no banho, com os 40 litros diários. No quinto e último trecho do vídeo, intitulado agora um desafio, as personagens propõem aos espectadores o desafio de produzir uma resposta, na forma de um vídeo digital, para a problemática apresentada no vídeo. Os modos comunicativos mobilizados nessa parte do vídeo são a oralidade direta das falas dos personagens e uma parte da música "Vou desafiar você", de autoria de MC Sapão. Além da fala e da música, essas cenas incluem uma parte em que as personagens dançam ao som da referida melodia e, em seguida, lançam o desafio aos espectadores.

Do ponto de vista da modelagem, os trechos do vídeo podem ser interpretados como segue. No primeiro, na hora do banho, temos a apresentação do tema da atividade. O garoto acrescenta à sua fala o fato de ter aprendido na escola sobre a importância da água para a vida em nosso planeta e convida os espectadores a acompanharem as medidas referentes ao consumo da água no chuveiro. Não temos base para afirmar o quanto o relato do garoto contribui para a atividade de modelagem em questão. Porém, trazer uma criança de oito anos para falar sobre suas impressões sobre o tema de uma atividade de modelagem em um ISSN 2526-2882

$$
\text { * } 184
$$


minicurso voltado para professores, pesquisadores e futuros professores é algo não usual e que foi favorecido pela mídia vídeo digital. Além disso, o vídeo favorece a atuação da criança ao permitir que a fala seja gravada repetida vezes, até que se consiga a forma desejada. Outro elemento que contribuiu com a performance do menino é o uso da legenda, que consiste em um recurso inerente à mídia vídeo, e que permite pontuar os pontos mais importantes da mensagem oral.

O segundo e o terceiro trechos do vídeo (coletando a água e medindo a água) referemse à apresentação dos dados empíricos. Ao permitir a reprodução dos processos de medida da água consumida no chuveiro no período de $10 \mathrm{~s}$, o vídeo traz uma maneira de comunicar esse resultado de uma forma que dificilmente seria possível com outra mídia. Esses processos empíricos trazem à cena instrumentos como o balde, o copo de medida e o cronômetro, que assumem papel protagonista nesse trecho do vídeo. A presença desses instrumentos, que não são necessariamente modernos, em uma experiência pedagógica desenvolvida com o suporte de uma tecnologia atual, como é o caso do vídeo digital, remete-nos a Borba e Villarreal (2005). Esses autores afirmam que a presença de uma nova tecnologia não substitui as outras, uma vez que essas mídias se moldam reciprocamente, assim como moldam a própria produção de conhecimentos, ao favorecerem a constituição de coletivos pensantes de seres-humanos-commídias qualitativamente novas.

Esse convívio entre velhas e novas tecnologias, que o vídeo permite, pode favorecer o desenvolvimento de trabalhos com modelagem em ressonância com o que acontece no cotidiano dessa sociedade digital que vivenciamos, hoje em dia. O copo de medida, por exemplo, é uma tecnologia ainda muito presente na cultura culinária, basta observar o trabalho das cozinheiras e cozinheiros. Porém, atualmente, essa tecnologia convive, por exemplo, com o smartphone, por meio do qual é possível acessar receitas culinárias disponíveis na internet. E muitas dessas receitas estão disponíveis na forma de vídeos digitais.

No quarto trecho, questões são propostas no intuito de comparar os resultados empíricos com dados disponíveis no site do Ministério do Meio Ambiente, e esses últimos com a água que os espectadores consomem durante o banho. Essa combinação de dados empíricos com dados obtidos na internet traz à tona questões levantadas por Diniz e Borba (2012) a respeito da presença de dados prontos em atividades de modelagem. Os autores apontam que esses dados obtidos a partir da internet, muitas vezes na forma de gráficos e tabelas, são tratados pelos alunos em seus trabalhos com modelagem da mesma forma que os dados produzidos empiricamente, sem que se busque qualquer explicação a respeito da maneira como foram obtidos. Nesse sentido, a mídia vídeo se apresenta como uma possibilidade de combinar o uso de dados empíricos com dados vindos da internet, o que permite, inclusive, confrontá-los. 
Contudo, a forma como as questões relacionadas aos dados empíricos e aqueles obtidos pela internet foram apresentadas suscita reflexões. As cenas do vídeo que apresentam essas questões se resumem à oralidade, que reproduz, quase que na íntegra, o texto que aparece escrito em uma imagem estática. Essa forma de apresentar as questões inclui modos comunicativos que se aproximam daqueles que são comuns à sala de aula presencial, onde o texto escrito na lousa e a oralidade do professor dominam a cena. Em outras palavras, entendemos que a maneira de apresentar essas questões pode ser interpretada como uma domesticação da mídia vídeo digital, ao "utilizá-la de forma a manter intacta práticas que eram desenvolvidas com uma mídia que é predominante em um determinado momento da produção de conhecimento" (BORBA; SCUCUGLIA; GADANIDIS, 2014, p. 25). Consideramos que essa domesticação pode ser vista como uma limitação das potencialidades do vídeo digital, que deve ser evitada na elaboração de futuros videoproblemas de modelagem.

Na próxima seção, descreveremos a atividade de modelagem desenvolvida pelos participantes a partir do vídeo (videoproblema de modelagem) que lhes foi apresentado. Essa atividade resultou no vídeo que produziram como resposta ao primeiro, ou seja, uma videorresposta de modelagem.

\section{O processo de modelagem e a videorresposta}

O vídeo que propôs a atividade foi apresentado ao longo do primeiro dia do minicurso, em 12/10/2018. Ainda nesse primeiro dia, os participantes se reuniram, em um grupo único, para deliberarem a respeito da produção do videorresposta. Logo se estabeleceu uma divisão de tarefas, de forma que alguns se dedicavam ao trabalho com modelagem desenvolvido a partir do que foi proposto no videoproblema, enquanto outros já pensavam no projeto do videorresposta. A pedido dos próprios participantes, o professor disponibilizou o documento a partir do qual alguns dos dados apresentados no videoproblema foram obtidos.

A modelagem desenvolvida consistiu, basicamente, da estimativa dos valores médios referentes ao consumo diário de água por pessoa, e da comparação desses valores com os parâmetros apresentados no documento do Ministério do Meio Ambiente. Não foi possível ao professor do minicurso, contudo, acompanhar, em detalhes, os processos pelos quais os resultados foram obtidos. A atividade culminou na produção de um videorresposta de modelagem ${ }^{26}$ pelos participantes, por meio da qual os resultados obtidos nas estimativas e as reflexões desenvolvidas foram apresentados.

No que se refere ao processo de modelagem, e também aos modos comunicativos mobilizados, esse vídeo pode ser dividido em duas partes. A primeira apresenta a filmagem de

${ }^{26} \mathrm{O}$ referido vídeo não pode ser tornado público por razões relativas à ética nas pesquisas em Educação, uma vez que contém a voz de alguns dos participantes, e não temos a autorização dos mesmos para a publicação do material. 
uma figura sendo construída na lousa por uma das participantes, de quem só aparece uma das mãos e parte do braço (Figura 6). A cena é acompanhada da narrativa de um segundo participante. A figura consiste de um retângulo que aparece, inicialmente, sem preenchimento interior, e que vai, gradativamente, sendo preenchido (colorido) pela mão da participante. Na parte superior do retângulo temos a inscrição 40 l, que aparece desde o início do vídeo. Esse valor corresponde ao consumo diário mínimo de água por pessoa, sugerido pela Organização Mundial de Saúde (OMS), conforme é informado no vídeo (videoproblema) que propôs a atividade e no documento do Ministério do Meio Ambiente. A intenção dos autores do vídeo, segundo informaram ao professor, era representar, por meio desse retângulo, um recipiente com a capacidade correspondente a esse consumo mínimo diário.

Figura 6: Sequência de imagens da cena do preenchimento gradativo doretângulo.

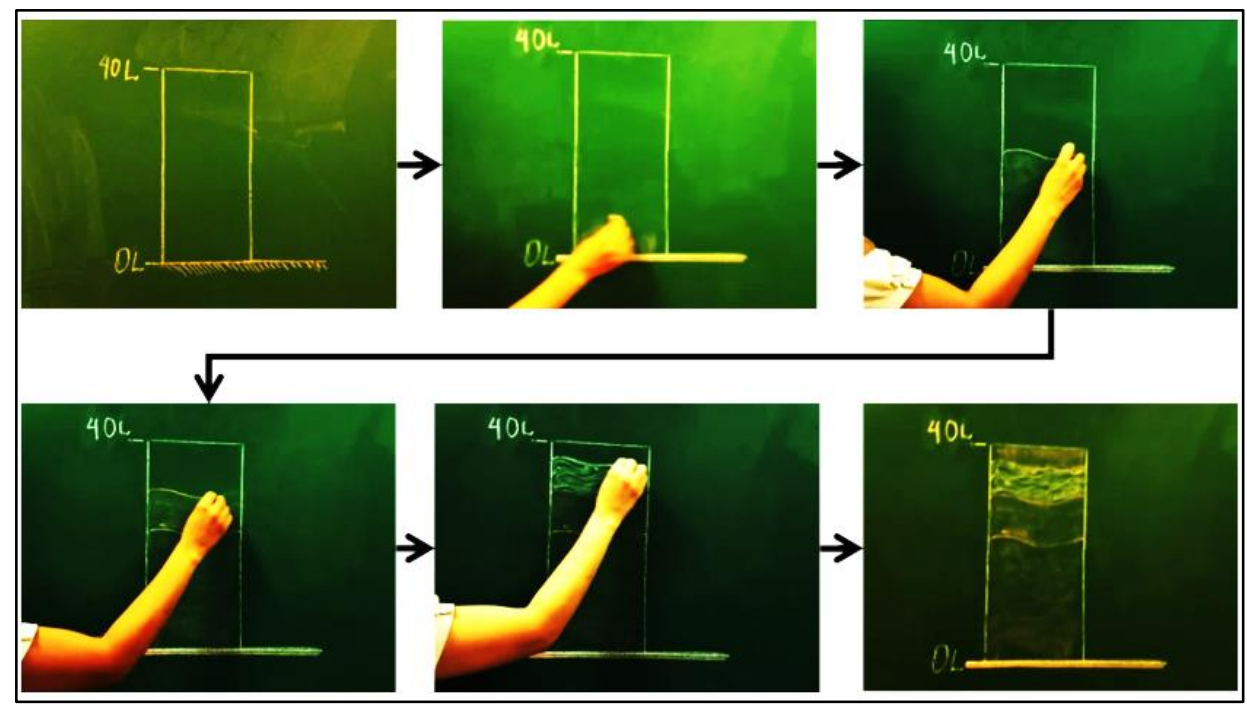

Fonte: Videorresposta produzida pelos participantes do minicurso.

À medida que o retângulo é colorido, linhas oblíquas vão sendo traçadas em seu interior. Essas linhas buscam mostrar as frações aproximadas do total de 40 l, correspondentes ao consumo de água estimado pelos participantes em algumas atividades do dia a dia. $\mathrm{O}$ tipo de atividade e a quantidade de água estimada para cada uma delas é informada apenas na narração que acompanha a construção da figura na lousa, pois esses valores não aparecem na imagem do filme. As atividades, assim como o tempo e a quantidade de água consumidos em cada uma delas, conforme as estimativas, são: 241 no banho, $10 \mathrm{l}$ em descarga no vaso sanitário, 5 l escovando os dentes e lavando as mãos, e 21 bebendo água.

Na segunda parte, os recursos comunicativos mobilizados continuam restritos à oralidade, em forma de narração, e ao desenho de figuras na lousa. Porém, em vez da filmagem que apresenta o movimento de uma figura sendo desenhada na lousa, temos duas imagens estáticas sendo apresentadas consecutivamente. Em ambas aparece o mesmo desenho de uma 
torneira, com a diferença de que na segunda surge um traço em forma de xis sobre a mesma (Figura 7). Além disso, a narração não é apresentada apenas pela voz que aparece na primeira parte, uma vez que surgem mais dois narradores. Nessa segunda parte do vídeo, o primeiro trecho é narrado por uma terceira participante, em um segundo momento surge a voz do professor do minicurso, enquanto que no terceiro trecho, o qual encerra o vídeo, a voz do narrador da primeira parte reaparece.

Figura 7: Sequência de imagem da cena da torneira sendo riscada com traços em forma de xis.

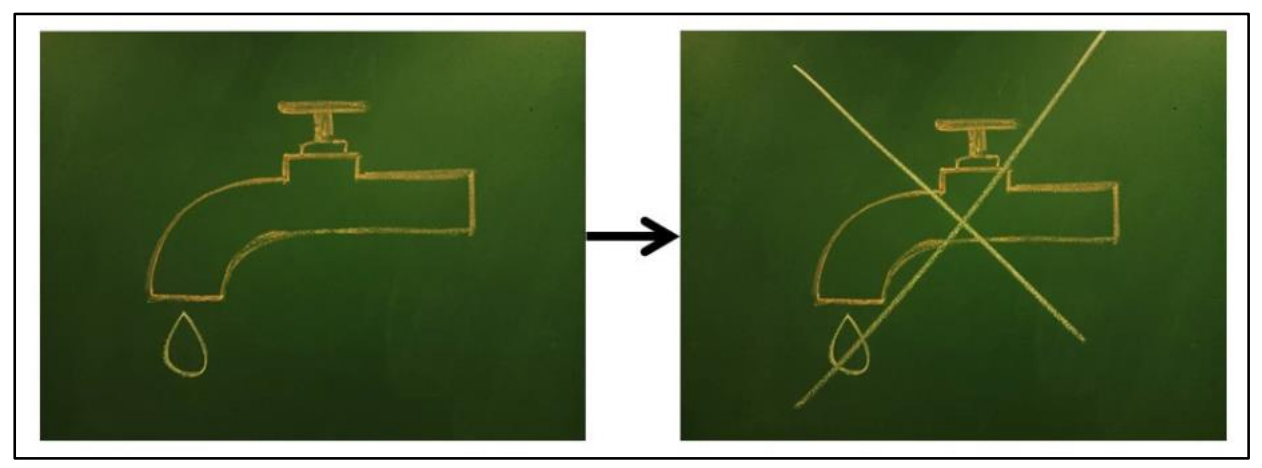

Fonte: Videorresposta produzida pelos participantes do minicurso.

As cenas dessa segunda parte do vídeo buscam mostrar a impossibilidade de restringir o consumo diário de água individual aos 40 l. Essa intenção é revelada no conteúdo da narrativa que menciona duas atividades - a saber: lavar a louça e o carro - para as quais não resta mais água, uma vez que os $40 \mathrm{l}$ já foram consumidos nas atividades mencionadas na primeira parte do vídeo. Essa insatisfação é comunicada por meio do próprio conteúdo da narração, pois os dois primeiros narradores mencionam em forma de pergunta como farão para lavar a louça e o carro, e o terceiro narrador responde, com certa dose de ironia, com a informação de que agora não se faz mais nada, pois a ONU fechou a torneira. O recurso da imagem da torneira sendo riscada por um traço em forma de xis, surge com uma metáfora que se associa à oralidade no sentido de reforçar a ideia da insatisfação com a recomendação da Figura 7: Sequência de imagem da cena da torneira sendo riscada com traços em forma de xis. Que, por ser um órgão ligado à Organização das Nações Unidas (ONU), dirigiu-se a essa última.

Ao olharmos para os recursos mobilizados nesses modos comunicativos e interpretativos, temos a lousa desempenhando papel central. A prevalência dessa mídia nos convida a refletir a partir de duas conjecturas. A primeira delas nos remete aos próprios pressupostos teóricos da semiótica social, os quais assumem que os modos comunicativos são produtos históricos e culturais dos contextos nos quais são comunicados e interpretados (Kress, 2009; Bezemer; Jewitt, 2010). Nesse sentido, o protagonismo da lousa nas cenas do vídeo poderia ser visto como uma manifestação dos modos comunicativos presentes na tradição da educação matemática escolar, na qual a explanação oral, combinada com a exibição 
de imagens desenhadas e textos escritos nessa mídia, são modos comunicativos e interpretativos dominantes.

Outra possível conjectura seria considerar os limitados recursos disponíveis aos autores do vídeo. O minicurso se limitava ao espaço físico da sala de aula e a dois encontros de duas horas cada um. Essas restrições de tempo e espaço podem ter sido determinantes na opção pelas imagens na lousa como recurso predominante. Uma discussão mais profunda dessas conjecturas demandaria a mobilização de métodos investigativos que estão além dos nossos interesses e das possibilidades desse estudo.

Da perspectiva do construto seres-humanos-com-mídias, cabe refletir sobre a ação da mídia software de edição nessa atividade de modelagem com produção de vídeos. Essa reflexão se tornou possível porque o professor não apenas participou dos processos de filmagens e gravação de áudios, atuando inclusive como um dos narradores, mas também porque a edição do vídeo foi feita em seu próprio notebook, por meio do software windows movie maker, de forma que o arquivo do projeto de edição do filme ficou armazenado na memória desse dispositivo.

Nesse processo de edição, o tempo de duração do filme que retrata a construção da figura na lousa, na primeira parte da videorresposta, é mais longo que o referente às narrações. Essas últimas foram gravadas em vários trechos, em diferentes arquivos de áudio, com a oralidade de três pessoas diferentes. Enquanto o filme, que foi gravado de maneira contínua, encontra-se em um único arquivo. A solução foi recortar o filme em várias cenas e alterar a velocidade de reprodução de cada uma delas de forma a ajustá-las aos áudios que as descreviam. E essa possibilidade de moldar a velocidade de um filme à oralidade permite formas qualitativamente novas de combinar recursos comunicativos e interpretativos em modos que são próprios à mídia software de edição.

Essa possibilidade de moldar a velocidade do filme à oralidade reconfigura a maneira como essas mídias se combinam nos modos comunicativos e interpretativos presentes na da sala de aula presencial, na qual a sequência das imagens em um projetor, ou mesmo o ritmo da escrita na lousa, condicionam a oralidade. A maneira como a oralidade se relaciona com o filme da construção da imagem, na videorresposta, remete-nos à noção de moldagem recíproca, que é central nas concepções epistemológicas subjacentes ao construto sereshumanos-com-mídias. A moldagem recíproca encontra inspirações nas ideias de Lévy (1993) a respeito da relação entre a oralidade e a escrita, ao considerar que a escrita não substituiu a oralidade, mas moldou a forma das pessoas se comunicarem oralmente. Por meio dessa afirmativa, o autor busca sustentar o argumento de que as tecnologias informáticas não irão substituir nem a oralidade e nem a escrita, mas que tendem a moldar suas características. Borba e Villarreal (2005) expandem essa noção ao considerarem que essa moldagem entre as 
distintas tecnologias (mídias) é recíproca e engloba, também, a relação entre humanos e mídias.

Entendemos que a forma como o filme se ajustou à oralidade no videorresposta - ou seja, foi moldado por ela - traz para os coletivos de seres-humanos-com-softwares-de-edição possibilidades que podem ser elucidadas sob os olhares teóricos do construto seres-humanoscom-mídias e da semiótica social. Uma indagação que desponta desse diálogo teórico remete à possibilidade das mídias, ao serem consideradas recursos comunicativos e interpretativos, assumirem o potencial de moldar a produção de conhecimentos quando combinadas em modos qualitativamente distintos. No exemplo supracitado, da lousa e da oralidade, deixamos às futuras pesquisas a conjectura de que os novos modos de combinar esses recursos (mídias), que o vídeo permite, moldam a produção de conhecimentos de maneira qualitativamente distinta daqueles que são produzidos a partir dos modos comunicativos que essas mesmas mídias (recursos comunicativos) historicamente protagonizam na sala de aula. Refletir sobre essa conjectura nos leva a indagar, até mesmo, se faz algum sentido considerar a lousa e a oralidade que aparecem no vídeo da mesma maneira que consideramos esses objetos na tradição da educação matemática escolar.

Ao refletirmos sobre o processo de modelagem desenvolvido, devemos considerar a maneira como a problemática foi proposta no videoproblema, desenvolvida pelos participantes, e respondida na videorresposta. A Figura 5 mostra que o videoproblema propõe duas questões como ponto de partida para o processo de modelagem. A primeira se refere à comparação entre os valores obtidos para a vazão do chuveiro no experimento empírico apresentado (800 ml em $10 \mathrm{~s}$ ) e aqueles informados no documento do ministério do meio ambiente (150 l em 10 minutos). A segunda problemática se volta para a água consumida pelo espectador no banho, e a que fração ela corresponde da quantidade diária mínima informada pelaOMS.

A forma como o processo de modelagem se desenvolveu, contudo, foi além dessas questões, uma vez que se voltou para o consumo diário de água de uma pessoa a partir de diversas atividades do dia a dia, e não apenas no banho. Esse processo se baseou em estimativas e comparações apoiadas nos dados apresentados tanto no videoproblema como no documento oficial disponibilizado aos participantes. Cabe-nos questionar a plausibilidade de desenvolver uma atividade de modelagem, a partir de estimativas e comparações, em vistas do nível escolar dos participantes do minicurso. Entendemos, de um lado, que estimativas e comparações são formas de matematizações que podem não configurar um problema - em razão dos poucos recursos mobilizados e esforços desprendidos para resolvê-lo - para um grupo de professores e estudantes de graduação e pós-graduação. Por outro lado, consideramos que a participação nessa atividade tem o potencial de apresentar possibilidades à prática letiva desses professores e futuros professores, tanto no que tange à modelagem como 
no que se refere à produção de vídeos, além de descortinar objetivos de pesquisas aos pósgraduandos participantes.

A maneira como os dados informados pelo Ministério do Meio Ambiente e os que foram obtidos empiricamente foram tratados nessa atividade de modelagem destaca o papel da mídia vídeo digital. A partir das observações do professor ao longo da atividade, foi possível notar que o resultado encontrado pelos participantes para a quantidade diária de água gasta com banho, que foi de 24 litros, considerou um banho de 5 minutos, o que mostra que levaram em conta os $800 \mathrm{ml}$ em $10 \mathrm{~s}$ obtidos empiricamente, e não os $150 \mathrm{l}$ em 10 minutos informados no documento, pois $800 \mathrm{ml}$ a cada $10 \mathrm{~s}$ equivalem a 4,8 $\mathrm{l}$ por minuto, o que conduz aos $24 \mathrm{l} \mathrm{em}$ 5 minutos.

A modelagem tem forte componente interdisciplinar, de forma que é usual a presença de experimentos de outras áreas do saber e mesmo do dia a dia em trabalhos com modelagem. Borba, Meneghetti e Hermini (1997) apresentam práticas de modelagem em que dados colhidos empiricamente combinaram-se com informações obtidas a partir da visualização da tela da calculadora gráfica, configurando uma aproximação entre a modelagem e a abordagem denominada por Borba e Villarreal (2005) experimental com tecnologias. Borba e Dinis (2012) discutem o divórcio das práticas de modelagem com a empiria diante da predominância de dados obtidos prontos a internet. Dados dessa natureza predominam, também, na atividade de modelagem descrita em Borba, Villarreal e Soares (2106). A presença da empiria nas cenas do videoproblema e a maneira como dados empíricos e obtidos da internet foram tratados no processo de modelagem desenvolvido pelos participantes leva-nos a indagar se será o vídeo aquele ator que promoverá a reconciliação entre procedimentos empíricos, dados prontos da internet e experimental com tecnologias.

Não é possível afirmarmos, baseados somente nesse estudo exploratório, até que ponto a apresentação do experimento empírico no videoproblema, de uma maneira que dificilmente seria possível por meio de outra mídia que não o vídeo digital, contribuiu para que os argumentos matemáticos do documento oficial fossem confrontados, da forma que foram. Mas, cabe destacar que essa atitude de confrontar os dados oficiais vai em direção às preocupações assumidas na perspectiva sociocrítica da modelagem, conforme são apresentados em Araújo (2012), pois configura uma forma de desafiar o status de certeza que esses argumentos matemáticos tendem a assumir, transformando o texto matemático em um discurso de poder (c. F. BORBA; SKOVSMOSE, 2001). As preocupações subjacentes à perspectiva sociocrítica não eram o objetivo do minicurso, assim como não é o tema central desse artigo. Porém, consideramos importante atentar para as possiblidades sociocríticas do vídeo digital, que podem vir a ser exploradas tanto na prática docente quanto em futuras pesquisas acadêmicas. 
Outro ponto importante refere-se às representações matemáticas que o vídeo possibilita. A figura em forma de retângulo que aparece sendo constituída no videorresposta pode ser vista como um modelo matemático, ou seja, uma maneira de representar, com a Matemática, uma situação não matemática. Ao considerar a noção de modelo matemático, autores como Bassanesi (2002) e Blum et al. (2007) atentam para as diferentes características e papéis que essas representações desempenham nos processos de modelagem. Porém, a construção de um modelo matemático a partir da produção de um vídeo digital - que envolve filmagens, gravações de áudio, dentre outros procedimentos, inclusive a edição de vídeo configura um processo qualitativamente novo que emerge quando a modelagem e a produção de vídeos se associam. Entendemos que compreender como novas matematizações se tornam possíveis quando a mídia vídeo digital está presente, é tema que merece espaço na agenda das pesquisas que envolvem modelagem.

\section{Considerações finais}

Neste artigo, apresentamos um ensaio a partir de um estudo exploratório que teve como contexto uma atividade de modelagem desenvolvida pelo segundo autor em um minicurso apresentado ao VIII EMEM. Essas reflexões perpassam nossa visão de conhecimento e modelagem, à luz dos pressupostos teóricos da análise multimodal, na perspectiva da semiótica social. As formas de compreender as tecnologias digitais e a semiótica começam a interagir em nossa compreensão do vídeo digital como ator educacional. As mídias, vistas como coautoras das expressões multimodais geradas, apresentam novas formas da matemática se expressar. Até que ponto essa matemática será transformada por essa nova forma de expressão é uma pergunta em aberto. A geometria praticada na escola definitivamente se modificou com o arrastar dos softwares digitais, ou com o grande número de gráficos de funções sendo gerados em pouco tempo. Parece-nos que da mesma forma que Borba e Villarreal (2005), há 15 anos atrás, sistematizavam a relação entre etnomatemática e a Matemática permeada por mídias (oralidade, lápis e papel e computadores), entendemos que o vídeo, que deixou de ser um meio de comunicação de massa e vem se tornando uma recurso (ou mídia) pelo qual as pessoas interagem cotidianamente no séculoXXI, pode também modificar a matemática, pensada por muitos como imutável.

Sobre a forma como a tarefa foi proposta no vídeo (videoproblema) consideramos, de um lado, as possibilidades desse ator tecnológico ao apresentar a problemática em um formato que dificilmente seria da mesma maneira com outra mídia. Por outro lado, apontamos que a maneira como as questões que direcionaram a atividade de modelagem a ser desenvolvida foram apresentadas nas cenas, com a oralidade limitada à leitura dos textos estáticos, sugere uma subutilização, ou domesticação, da mídia vídeo digital, a qual se faz necessário superar na elaboração de futuros videoproblemas de modelagem. 
A respeito das possibilidades do vídeo digital que foram exploradas no videoproblema, merece destaque o fato dessa tecnologia permitir mostrar todo o desenvolvimento do experimento empírico e não apenas o dado obtido a partir dele, em uma associação entre tecnologias digitais, como smartphone e softwares de edição, com recurso que resistem ao tempo, a exemplos do balde e do copo de medida, ainda tão presentes nas atividades culinárias. Essa possibilidade do vídeo de trazer a experimentação empírica para as cenas, combinada ao potencial interdisciplinar da modelagem, leva-nos a indagar: será o vídeo aquele ator que aproximará a experimentação com softwares, que acontece em abordagens apoiadas no enfoque experimental-com-tecnologias, dos processos empíricos baseados em tecnologias não digitais, como a régua, o compasso, a fita métrica, o cronômetro, o copo de medida, etc.?

$\mathrm{Na}$ atividade de modelagem desenvolvida a partir do videoproblema, o fato de o vídeo permitir mostrar a empiria, o experimento, e não apenas o seu resultado traduzido como números, pode ter contribuído para que os participantes optassem pelo valor obtido empiricamente em vez do dado oficial que lhes foi apresentado. Essa opção pelos dados empíricos pode ser vista como um questionamento do status de certeza dos argumentos matemáticos, o que sugere um potencial sociocrítico da mídia vídeo digital em atividades de modelagem.

Além disso, novas problematizações emergiriam e outras conjecturas foram levantadas para além do que foi proposto no videoproblemas, o que se exemplifica na problematização levantada pelos participantes a respeito da possibilidade de limitar o consumo diário de água, por pessoa, aos $40 \mathrm{l}$ sugeridos pela OMS. Isso sugere que, além da resolução de problemas, a modelagem desenvolvida por meio de videoproblemas e videorrespostas permite a proposição de novos problemas pelos alunos.

Ressaltamos, ainda, a forma como os recursos comunicativos foram mobilizados pelos participantes na produção da videorresposta. O protagonismo da lousa e da oralidade nas cenas dessa videoprodução pode ser visto como a manifestação da tradição da cultura escolar, na qual essas mídias tendem a ser predominantes. Em contrapartida, é preciso levar em conta as condicionantes relativas ao contexto, que não oferecia muitos outros recursos, além do tempo relativamente curto para a inclusão de outros modos de comunicação de significados.

Consideramos que as reflexões apresentadas neste artigo revelam possibilidades da mídia vídeo digital em abordagens pedagógicas apoiadas na modelagem. Entendemos que levar para as práticas de modelagem os recursos de uma tecnologia cada vez mais presente nas relações sociais contemporâneas pode ser um caminho para que a modelagem, enfim, se popularize nas salas de aulas de Matemática, tanto presenciais como online, de todos os níveis educacionais. Acrescentamos, finalmente, a importância das potencialidades pedagógicas que 
emergem dessa aproximação entre produção de vídeos e modelagem ganhar espaço na agenda das pesquisas em modelagem.

\section{Referências}

ALMEIDA, l. W.; VERTUAN, R. E. Discussões sobre “como fazer” modelagem na sala de aula. In: almeida, l. M. W.; araújo, j. L.; bisognin, e. (orgs.). Práticas de modelagem matemática: relatos de experiências e propostas pedagógicas. Londrina (pr): eduel, 2011. P. 19-43.

ARAÚJO, J. L. Cálculo, tecnologias e modelagem matemática: as discussões dos alunos. 2002. 173f. Tese (doutorado em educação matemática) - instituto de geociências e ciências exatas, universidade estadual paulista, rio claro, 2002.

BASSANESI, R. C. Ensino-aprendizagem com modelagem matemática: uma nova estratégia. São paulo: contexto, 2002.

BEZEMER, J; JEWITT, C. Multimodal analysis: key issues. In: litosseliti, l. (ed.) Research methods in linguistics. London: continuum international publishing group, 2010. P. 180-197.

BIEMBENGUT, M. S. 30 anos de modelagem matemática na educação brasileira: das propostas primeiras às propostas atuais. Alexandria - revista de educação em ciência e tecnologia, v.2, n.2, p.7-32, jul. 2009.

BIEMBENGUT, M. S.; HEIN, N. Modelagem matemática no ensino. São paulo: contexto, 2000.

BLUM, W. Quality teaching of mathematical modelling: what do we know, what can we do? In: cho, s. J. (ed.) The proceedings of the 12th international congress on mathematical education: intellectual and attitudinal changes. New york: springer international publishing, 2015. P. 73-96.

BLUM, W.; GALBRAITH, P. L. HENN, H-W.; niss, m. (ed.) Modeling and applications in mathematics education: the 14th icmi study. New york: springer editor, 2007.

BORBA, M. C. Potential scenarios for internet use in the mathematics classroom. Zdm mathematics education, v. 41, n. 4. P. 453-465, 2009. Doi: 10.1007/s11858-0090188-2

BORbA, M. C.; ALMEIDA, H. R. F. L.; GRACIAS, T. A. S. Pesquisa em ensino e sala de aula: diferentes vozes em uma investigação. Belo horizonte: autêntica editora, 2018. 125p.

BORBA, M. C.; MENEGHETTI, R. C. G.; HERMINI, H. A. Modelagem, calculadora gráfica e interdisciplinaridade na sala de aula de um curso de ciências biológicas. Revista de educação matemática da sbem-sp, v. 5, n. 3, p. 63-70, 1997. 
BORBA, M. C.; SCUCUGLIA, R. R. S.; GADANIDIS, G. Fases das tecnologias digitais em educação matemática: sala de aula e internet em movimento. Belo horizonte: autêntica editora, 2014.

BORBA, M. C.; SKOVSMOSE, O. A ideologia da certeza em educação matemática. In: skovsmose, o. (org.) Educação matemática crítica: a questão da democracia. Campinas: papirus, 2001. P.127-148.

BORBA, M. C.; VILLARREAL, M. E. Humans-with-media and the reorganization of mathematical thinking: information and communication technologies, modeling, experimentation and visualization. V. 39, new york: springer, 2005.

BORBA, M. C.; VILLARREAL, M. E.; SOARES, D. S. Modeling using data available on the internet. In: christian r. Hirsch; amy roth mcduffie. (org.). Mathematical modeling and modeling mathematics. Annual perspectives in mathematics education. United states of america: nctm national council of teachers of mathematics, p. 143152, 2016.

BRASIL, MINISTÉRIO DO MEIO AMBIENTE. Consumo sustentável: manual de educação. Brasília: consumers international/ mma/ mec/idec, 2005. $160 \mathrm{p}$. Disponível em:

http://www.mma.gov.br/estruturas/educamb/_arquivos/consumo_sustentavel.pdf $>$, último acesso em 04/07/2019.

BURAK, D. Uma perspectiva de modelagem matemática para o ensino e a aprendizagem da matemática. In: brandt, c. F.; burak, d.; klüber, t. E. (orgs.). Modelagem matemática: perspectivas, experiências, reflexões e teorizações. 2 ed. Ponta grossa: editora uepg, 2016. P. 17-40.

DINIZ, L. N. O papel das tecnologias da informação e comunicação nos projetos de modelagem matemática. 2007. 131f. Dissertação (mestrado em educação matemática) - instituto de geociências e ciências exatas, universidade estadual paulista, rio claro, 2007.

DINIZ, L. N.; BORBA, M. C. Leitura e interpretação de dados prontos em um ambiente de modelagem e tecnologias digitais: o mosaico em movimento. Bolema, rio claro (sp), v. 26, n. 43, p. 935-962, ago. 2012.

ser crítico em projetos de modelagem em uma perspectiva da crítica de educação matemática. Bolema, v. 26, n. 43, p. 839-859, 2012.

DOMINGUES, N. S. O papel do vídeo nas aulas multimodais de matemática aplicada: uma análise do ponto de vista dos alunos. 2014. 128f. Dissertação (mestrado em educação matemática) - instituto de geociências e ciências exatas, universidade estadual paulista, rio claro, 2014. 
DOMINGUES, N. S.; BORBA, M. C. Vídeos digitais nos trabalhos de modelagem matemática.

Educação matemática em revista, v. 22, p. 38-50, 2017.

EISENSTEIN, S. A forma do filme. Rio de janeiro: zahar, 2002

FONTES, B. C. Vídeo, comunicação e educação matemática: um olhar para a produção dos licenciandos em matemática da educação a distância. 2019. 191f. Dissertação (mestrado em educação matemática) - instituto de geociências e ciências exatas, universidade estadual paulista, rio claro, 2019.

FREIRE, P. Pedagogia do oprimido. 50. Ed. São paulo: paz e terra, 2011.

GALleGuilloS, J. E. B. Modelagem matemática na modalidade online: análise segundo a teoria da atividade. 2016. 215f. Tese (doutorado em educação matemática) - instituto de geociências e ciências exatas, universidade estadual paulista, rio claro, 2016.

GALLEGUILlOS, J. E. B.; BORBA, M. C. Expansive movements in the development of mathematical modeling: analysis from an activity theory perspective. $\mathbf{Z d m}$ journal - mathematics education, v. 50, issue 1-2, p. 129-142, 2018.

KRESS, G. Multimodality: a social semiotic approach to communication. London: routledgefalmer, 2009.

LÉVY, P. As tecnologias da inteligência: o futuro do pensamento na era da informática. Tradução carlos irineu da costa. São paulo: editora 34, 1993.

MALHEIROS, A. P. S. Educação matemática online: a elaboração de projetos de modelagem. 2008. 187f. Tese (doutorado em educação matemática) - instituto de geociências e ciências exatas, universidade estadual paulista, rio claro, 2008.

MALHEIROS, A. P. S.; FRANCHI, R. H. O. L. As tecnologias da informação e comunicação nas produções sobre modelagem no gpimem. In: Borba, m. C.; chiari, a. (org.). Tecnologias digitais e educação matemática. São paulo: editora livraria da física, 2013. P. 175-189.

MEYER, J. F. C. A.; CALDEIRA, A. D.; MALHEIROS, A. P. S. Modelagem em educação matemática. Belo horizonte: autêntica, 2011.

MOLETTA, A. Você na tela: criação audiovisual para a internet. São paulo: summus, 2019.

O’HALlORAN, K. L. Análisis del discurso multimodal. Revista latinoamericana de estudios del discurso, v. 12, n.1, p. 75-97, 2012.

OECHSLER, V. Comunicação multimodal: produção de vídeos em aulas de matemática. 2018. 311f. Tese (doutorado em educação matemática) - instituto de geociências e ciências exatas, universidade estadual paulista, rio claro, 2018.

OLIVEIRA, L. P. F. Paulo freire e produção de vídeos em educação matemática: uma experiência nos anos finais do ensino fundamental. 2018. 107f. Dissertação 
(mestrado em educação matemática) - instituto de geociências e ciências exatas, universidade estadual paulista, rio claro, 2018.

RENÓ, D. P. Cinema documental interativo e linguagens audiovisuais participativas: como produzir. La laguna (tenerife): sociedad latina de comunicación social, 2011. 111p.

SCUCUGLIA, R. R. S. On the nature of students' digital mathematical performances: when elementary school students produce mathematical multimodal artistic narratives. Germany: verlag - lap lambert acedemic publishing, 2012.

SOARES, D. S. Uma abordagem pedagógica baseada na análise de modelos para alunos de biologia: qual o papel do software? 2012. 341 p. Tese (doutorado em educação matemática) - instituto de geociências e ciências exatas, universidade estadual paulista, 2012.

SOARES, D. S.; BORBA, M. C. The role of software modellus in a teaching approach based on model analysis. Zdm journal - mathematics education, v. 46, issue 4, p. 575$587,2014$.

STILLMAN, G. A.; BLUM, W.; BIEMBENGUT, M. S. Cultural, social, cognitive and research influences on mathematical modelling education. In: stillman, g. A.; Blum, w.; Biembengut, m. S. (ed.). Mathematical modelling in education research and practice. New york: new york: springer international publishing, 2015. P. 1-32.

TIKHOMIROV, O K. The psychological consequences of computarization. In: wertsch, j. V. (ed.) The concept of activity in soviet psychology. New york: m. E. Sharpe, p. 256-278, 1981.

Apoio

O presente trabalho foi realizado com apoio da Coordenação de Aperfeiçoamento de Pessoal de Nível Superior - Brasil (CAPES) - Código de Financiamento 001. Consiste em uma ação do projeto apoiado pelo Conselho Nacional de Desenvolvimento Científico e Tecnológico (CNPq), a partir dos editais: Produtividade em Pesquisa (Processo: 303326/2015-8) e Universal (Processo: 400590/2016-6).

\section{Biografia Resumida}

Marcelo de Carvalho Borba: Licenciado em Matemática pela Universidade Federal do Rio de Janeiro (UFRJ). Mestre em Educação Matemática pela Universidade Estadual Paulista 'Julio ISSN 2526-2882

$$
\text { * } 197 *
$$


de Mesquita Filho' - campus de Rio Claro (UNESP - Rio Claro), São Paulo. Doutor nessa mesma área pela Cornell University, Estados Unidos. É professor do Programa de Pós-Graduação em Educação Matemática da UNESP - Rio Claro, São Paulo. Coordenador do Grupo de Pesquisa em Informática, Outras Mídias e Educação Matemática (GPIMEM).

Lattes: http://lattes.cnpq.br/4055717099002218

Contato: marcelo.c.borba@unesp.br

Neil da Rocha Canedo Junior: Licenciando em Matemática pela Faculdade de Filosofia Ciências e Letras de Valença (FAFIVA). Mestre em Educação Matemática pela Universidade Federal de Juiz de Fora (UFJF). Doutorando do Programa de PósGraduação em Educação Matemática da Universidade Estadual Paulista 'Julio de Mesquita Filho' - campus de Rio Claro, São Paulo. É professor da rede municipal de Educação de Juiz de Fora, Minas Gerais. Membro do Grupo de Pesquisa em Informática, Outras Mídias e Educação Matemática (GPIMEM). Lattes: http://lattes.cnpq.br/4354260366471746

Contato: neilcanedo@gmail.com 